\title{
A practical synthesis of L-threo-dihydrosphingosine (safingol), an antineoplastic and antipsoriatic agent
}

\author{
Lian Hao Zhang, ${ }^{\mathrm{a}}$ Daniela C. Oniciu, ${ }^{\mathrm{a}, \mathrm{b}}$ Ralf Mueller, ${ }^{\mathrm{a}}$ Bruce H. McCosar, ${ }^{\mathrm{a}}$ and Emil Pop ${ }^{\mathrm{a} *}$ \\ ${ }^{a}$ Alchem Laboratories Corporation, 13305 Rachael Boulevard, Alachua FL 32615, USA \\ ${ }^{b}$ Current address: Department of Chemistry, University of Florida, Gainesville, \\ FL 32611-7200, USA \\ E-mail:emilpop@alchem.com
}

\section{Dedicated to Professor Alexandru T. Balaban on his $75^{\text {th }}$ birthday}

(received 30 Jun 05; accepted 11 Oct 05; published on the web 12 Oct 05)

\begin{abstract}
$\mathrm{L}_{\mathrm{S}}$-threo-Dihydrosphingosine, an antineoplastic and antipsoriatic drug, has been synthesized by the Henri reaction of hexadecanal and 2-nitroethanol followed by catalytic hydrogenation of the dl-threo-2-nitro-1,3-octadecanediol and resolution of the racemic dl-threo-dihydrosphingosine. Selection of solvents for recrystallization of mixtures of dl-threo and erythro diastereoisomers proved to be of critical importance for the 100-gram scale preparation of the target compound.
\end{abstract}

Keywords: L-threo-Dihydrosphingosine, safingol, diastereoisomerism, optical resolution

\section{Introduction}

(2S,3S)-2-Amino-1,3-octadecanediol (L-threo-dihydrosphingosine or safingol, CAS \# 15639-506) (1), an antineoplastic and antipsoriatic drug, ${ }^{1}$ has been extensively studied for its role in cell regulation, signal transduction, ${ }^{2}$ and inhibition of protein kinase $C .^{3}$<smiles>CCCCCCCCCCCCCCO</smiles>

Safingol has two structurally nonequivalent asymmetrical carbon atoms and, accordingly, three more configurational isomers: the D-threo diastereoisomer (6, Scheme 1) and two erythro forms, 8 and the natural D-erythro-dihydrosphingosine (10). There are two general synthetic routes to safingol described in the literature: (i) diastereoselective or enantioselective methods 
that lead directly to the desired products; (ii) non-stereoselective methods that result in racemic mixtures, which are subsequently subjected to resolution. All these methods were described at milligram-scale and no attempts were made previously to produce safingol at a larger scale. The two-step enantioselective nitroaldol condensation (Henri reaction) of hexadecanal (2) with nitroethanol (3), followed by hydrogenation to $\mathrm{L}_{\mathrm{s}}$-threo-dihydrosphingosine; ${ }^{4}$ the total synthesis departing from 2(Z)-2-buten-1,4-diol (eight steps) ${ }^{5}$ the eight-step procedure starting from palmytoyl chloride having the asymmetric borane reduction of an $\alpha$-oxoketoxime trityl ether as a key step; ${ }^{6}$ and the diastereoselective synthesis via addition of $N$-hexyl magnesium bromide to the chiral 2,2-dimethylpropionic acid 4(S)-formyl-2,2-dimethyloxazolidin-3-yl ester, ${ }^{7}$ are procedures belonging to the first category. The synthesis of the threo 2-nitro-octadecane-1,3-diol by nitroaldol condensation, reduction of the nitroaldol to racemic dihydrosphingosine and subsequent optical resolution $^{8-10}$ illustrate the second type of syntheses. The most appealing procedure is the enantioselective nitroaldol condensation/reduction. An optically active BINOLlanthanium complex was the catalyst used to induce stereoselectivity in the condensation of hexadecanal with nitroethanol. However, the preparation of the catalyst was a three-step synthesis, ${ }^{4,11}$ which raises a series of technological problems, such as continuous cooling for more than 160 hours at temperatures below $-40{ }^{\circ} \mathrm{C}$. Although the amount of catalyst required for the reaction is low $(10 \mathrm{~mol} \%)$, the starting materials required for its preparation are quite expensive. Moreover, the synthesis of the chiral catalyst and its ligand are restricted by a recent patent. $^{12}$

Although a previously described diastereoselective synthesis ${ }^{7}$ reported an overall yield of the reaction of $c a .30 \%$ and seems appealing and elegant, the starting oxazolidine-type synthetic auxiliary had to be obtained by a multi-step synthesis, which makes it unsuitable for large-scale manufacture. ${ }^{13,14}$

Non-stereoselective syntheses are mostly alternatives to the Henry nitroaldol condensation (Scheme 1). This classic method is performed under diverse catalytic conditions and has been frequently reviewed. $^{15,16}$ The synthesis of 2-nitrooctadecane-1,3-diol starting from 2 and 3 has been described earlier, for both diasteromers and their mixtures. ${ }^{8-10}$ The mixture of nitrodiol diastereomers $(4+5$ and $7+9)$ was recrystallized from various solvents to give one single isomer. Diastereoselective methods described for the nitroaldol condensation, ${ }^{15-17}$ usually do not apply to long chain aldehydes. ${ }^{18}$ Methods based on stereoselective syntheses, although successful on small scale, often failed to reproduce the expected purity on larger scale. ${ }^{19}$ Finally, the reduction of the nitroaldol to the racemic mixture $(\mathbf{1}+\mathbf{6})$ followed by resolution has been described earlier. 8,10 


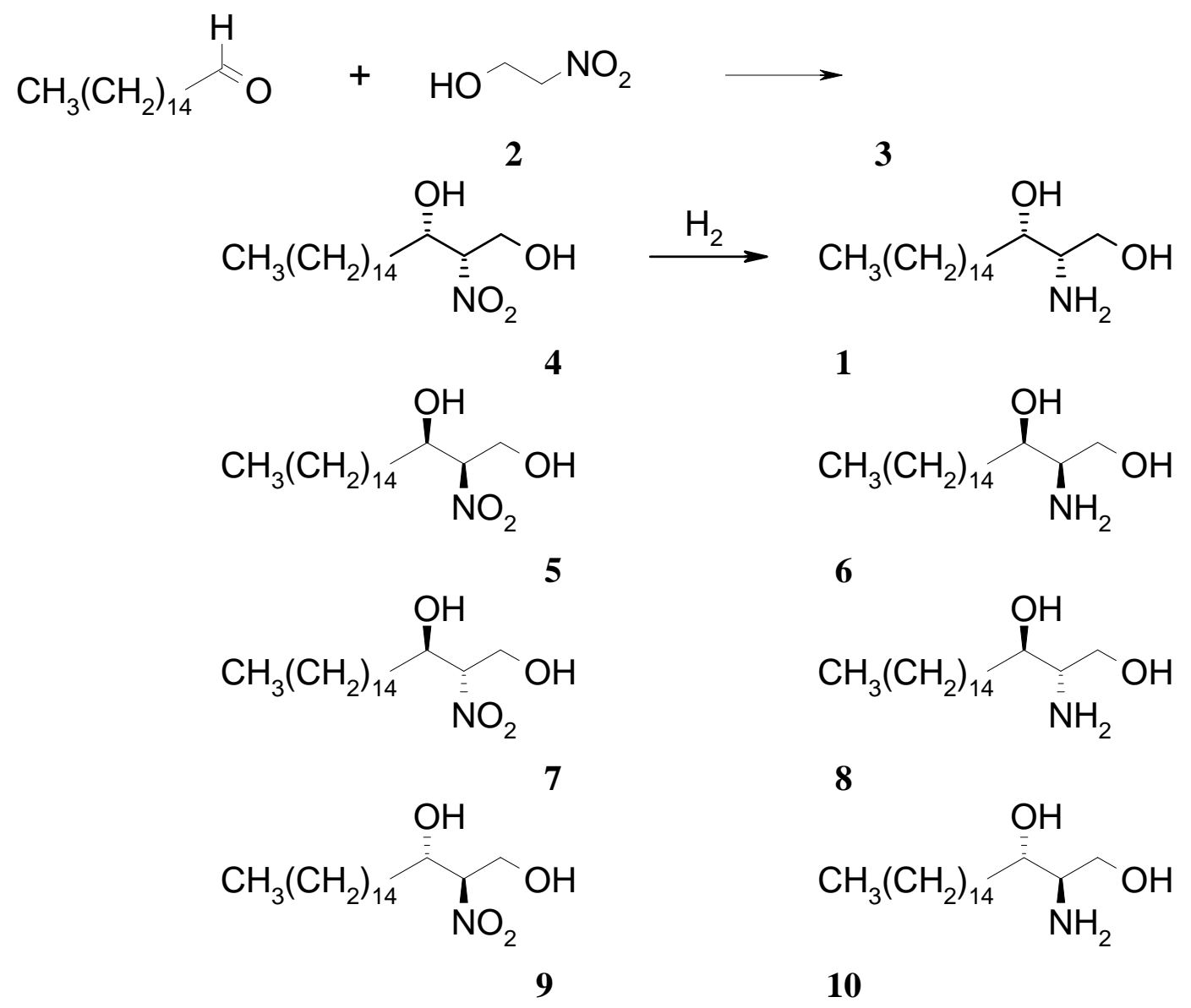

\section{Scheme 1}

\section{Results and Discussion}

Based on preliminary experiments, involving optimization of the catalyst and solvent, we have developed a simple three-step procedure for the 100-g scale production of safingol starting from commercially available hexadecanal, following the chemistry indicated in Scheme 1.

The most difficult issue to overcome was the selection of different solvent systems in order to separate dl-threo-2-nitro-1,3-octadecanediol from the reaction mixture which contained dlerythro-2-nitro-1,3-octadecanediol. We found that pentane : diethyl ether (7: 1, v/v) was an appropriate solvent system which provided the desired diastereoisomer with $>95 \%$ de. We discuss below the systems selected and the final results.

Hexadecanal (2) was condensed with 2-nitroethanol (3) in the presence of triethylamine with a reported yield in the range of 40-50\%. ${ }^{21}$ Pure dl-threo-2-nitro-1,3-octadacanediol (4+5) was obtained by recrystallization of the crude product from ether-pentane (yield 20\%). The second step, the hydrogenation, was performed in ethanol in the presence of $\mathrm{Pd}-\mathrm{C}$ with a $60-80 \%$ yield. The resolution of the resulting racemic mixture $(\mathbf{1}+\mathbf{6})$ consisted of precipitation of the glutamate 
of the D-isomer 6, followed by concentration of the mother liquors and subsequent recrystallization of the resulting $\mathrm{L}_{\mathrm{s}}$-threo-dihydrosphingosine glutamate. The free $\mathrm{L}_{\mathrm{s}}$-threodihydrosphingosine (1) was finally released by treatment of the salt with $\mathrm{Na}_{2} \mathrm{CO}_{3}$ in chloroform with a $c a .6 \%$ overall yield calculated from hexadecanal.

dl-threo-2-Nitro-1,3-octadacanediol. Pure dl-threo-2-nitro-1,3-octadecanediol was initially obtained as described in the literature with a de of 50\%. Recrystallization of mixtures of dl-threo and erythro diastereoisomers from ether/pentane gave yields of 20\%. Several diastereoselective methods that have been described in the literature found application for smaller chain aldehydes. Although most of the methods produce a mixture enriched in the erythro isomer, several procedures claim significant enrichment in the targeted threo diastereomer $(d e>70 \%)$. These methods are: diastereoselective aldol condensations performed via doubly deprotonated nitroalcohols ( $\alpha$-lithio nitronates); ${ }^{18,21}$ in the presence of titanium complexes, ${ }^{22}$ trialkylsilyl chlorides, ${ }^{23,24}$ or miscellaneous salts, such as tetrabutyl ammonium fluoride, ${ }^{25}$ and calcium and magnesium chloride. We investigated these methods for the reaction of hexadecanal and nitroethanol: In our experiments, yields of the desired diastereomer having de $>95 \%$ were between 10-20\%. Therefore, the aldol condensation was experimented by employing a series of catalysts and solvents with the aim of enriching one diastereomer in the reaction mixture in a reproducible manner. The following two procedures presented synthetic interest in terms of feasibility, reproducibility and cost effectiveness: (i) By using $\mathrm{Al}_{2} \mathrm{O}_{3}$ as catalyst and THF as solvent, $^{26}$ pure dl-threo-2-nitro-1,3-octadecanediol was obtained, but the yield after recrystallization was poor $(9.6 \%)$. Therefore, this procedure was abandoned. (ii) Employing triethylamine as both catalyst and solvent, ${ }^{20}$ the isolated yield was $19.4 \%$. This step was performed at a larger scale resulting in $100 \mathrm{~g}$ of final dl-threo-2-nitro-1,3-octadecanediol.

dl-threo-Dihydrosphingosine. The literature mentions two methods of hydrogenation that preserve the configuration. One uses $\mathrm{Pd}-\mathrm{C}$ as catalyst, ${ }^{4}$ the other uses Raney nickel ${ }^{8,24}$ as catalyst. Reports on hydrogenations with other reagents such as lithium borohydride or lithium aluminum hydride are not consistent in terms of preservation of the configuration. ${ }^{15-17}$ Therefore a few attempts of these reactions were performed in order to determine their applicability to our case. We found that during hydrogenation using Raney nickel as catalyst, for larger scale experiments the threo-nitro derivative epimerized under formation of the two amino diastereoisomers, as shown by NMR spectra of the reaction mixtures. Similarly, a mixture of diastereomers was obtained when using lithium aluminum hydride as reducing agent. The successful method was the hydrogenation with hydrogen at atmospheric pressure in the presence of Pd-C as catalyst, where the conversion to the dl-threo-dihydrosphingosine (mp 98-100 ${ }^{\circ} \mathrm{C}$ ) went smoothly in $77 \%$ yield.

In a large scale experiment, $65 \mathrm{~g}$ (74\% yield) of dl-threo-dihydrosphingosine was produced starting from $100 \mathrm{~g}$ of dl-threo-2-nitro-1,3-octadecanediol.

L-threo-Dihydrosphingosine. The racemic mixture obtained after hydrogenation was subjected to resolution with L-glutamic acid similar to a method that was reported at milligram-scale. ${ }^{10}$ Initially, we developed the method at gram-scale and we obtained the desired product in $c a .35 \%$ 
yield. In a large batch, $100 \mathrm{~g}(332 \mathrm{mmol})$ of dl-threo-dihydrosphingosine was resolved in a similar manner to give $24.2 \mathrm{~g}(48.4 \%)$ of (-)-threo-dihydrosphingosine). $[\alpha]_{\mathrm{D}}^{25}=-11.03^{\circ}(c 0.29$, $\mathrm{CHCl}_{3} / \mathrm{MeOH}=10 / 1$ ) and ee of $95.3 \%$, as needed for biological experiments. We have repeated the procedure three times and concluded that the method is reproducible.

\section{Conclusions}

We have developed a 100-g scale procedure for the preparation of safingol that meets criteria for industrial development: the procedure involves less than five synthetic steps, is reproducible, utilizes readily available raw materials, lacks hazardous by-products and waste, and uses common industrial solvents and catalysts.

\section{Experimental Section}

General Procedures. Chemical reagents from Sigma-Aldrich, Acros, or Lancaster were used without further purification. ACS grade solvents from Fisher Scientific or Mallinckrodt were routinely used for recrystallizations and extractions. Melting points (uncorrected) were determined on either a Thomas-Hoover capillary or Haake-Buchler melting point apparatus. ${ }^{1} \mathrm{H}$ NMR spectra were recorded at $300 \mathrm{MHz}$ and ${ }^{13} \mathrm{C}$ NMR spectra at $75 \mathrm{MHz}$ and ambient temperature on Varian NMR spectrometers. Chemical shifts for proton NMR are given in parts per million downfield from an internal tetramethylsilane standard and ${ }^{13} \mathrm{C}$ chemical shifts are calibrated on the $\mathrm{CDCl}_{3}$ resonance at $77.23 \mathrm{ppm}$, unless otherwise specified. Coupling constants $(J)$ are given in Hz. The purity of target compounds was analyzed using Shimadzu HPLC systems equipped with UV and/or RI detection.

dl-threo-2-Nitro-1,3-octadecanediol (4). In a 12-L flask, were added 1-hexadecanal (2) (750 g, $2.96 \mathrm{~mol}$ ), nitroethanol (3) (313 g, $3.34 \mathrm{~mol})$ and triethylamine (5 L). The mixture was stirred under nitrogen at room temperature for two days. Triethylamine was removed under reduced pressure. The residue was dissolved in tert-butyl methyl ether $(3750 \mathrm{~mL})$ and washed with $5 \%$ $\mathrm{HCl}(3 \times 1100 \mathrm{~mL})$ and dried over anhydrous $\mathrm{Na}_{2} \mathrm{SO}_{4}$. The solvent was removed under vaccum. The residue was recrystallized from a mixture of ether-pentane $(1500 \mathrm{~mL}$, diethyl ether : pentane $=1: 7 \mathrm{v} / \mathrm{v})$ at $20-25{ }^{\circ} \mathrm{C}$ and then from ether-pentane $(940 \mathrm{~mL}, 1: 7, \mathrm{v} / \mathrm{v})$ to obtain pure rac-2-nitro1,3-octadecanediol (4+5) $(190.4 \mathrm{~g}, 19.4 \%)$ as a light yellow powder. $\mathrm{Mp}=76-91{ }^{\circ} \mathrm{C} .{ }^{1} \mathrm{H} \mathrm{NMR}$ $\left(300 \mathrm{MHz}, \mathrm{CDCl}_{3}\right): \delta 4.62-4.52(\mathrm{~m}, 1 \mathrm{H}), 4.22-3.98(\mathrm{~m}, 3 \mathrm{H}), 2.46(\mathrm{~s}, 2 \mathrm{H}), 1.80-1.00(28 \mathrm{H}), 0.86$ $(\mathrm{t}, J=8.1 \mathrm{~Hz}, 3 \mathrm{H}) .{ }^{13} \mathrm{C} \mathrm{NMR}\left(75 \mathrm{MHz}, \mathrm{CDCl}_{3}\right): \delta 92.2,70.3,61.7,33.6,31.9,29.7,29.6,29.6$, 29.5, 29.4, 29.3, 29.3, 25.3, 22.7, 14.1.

dl-threo-Dihydrosphingosine (1+6). In a 12-L flask, were added rac-threo-2-nitro-1,3octadecanediol (4+5) $(100 \mathrm{~g}, 0.292 \mathrm{~mol})$ and absolute ethanol $(6.2 \mathrm{~L})$. The air from the flask was 
removed under vacuum, followed by three purging with argon. Pd-C (35 g, $10 \%$ ) was then added. The argon was then removed under vacuum and the flask was purged three times with hydrogen. The reaction mixture was stirred at atmospheric pressure and room temperature for 25 $\mathrm{h}$ under hydrogen. The catalyst was removed by filtration and washed with ethanol $(3 \times 50 \mathrm{~mL})$. The filtrate was concentrated to dryness. The residue was recrystallized from $95 \%$ ethanol $(900 \mathrm{~mL})$ to give rac-2-amino-1,3-octadecanediol $(\mathbf{1}+\mathbf{6})(62 \mathrm{~g}, 74.9 \%) . \mathrm{Mp}=97-99^{\circ} \mathrm{C} .{ }^{1} \mathrm{H} \mathrm{NMR}$ $\left(300 \mathrm{MHz}, \mathrm{CDCl}_{3}\right): \delta 3.73-3.52(\mathrm{~m}, 3 \mathrm{H}), 2.78-2.73(\mathrm{~m}, 1 \mathrm{H}), 2.4-1.8(\mathrm{w}, 4 \mathrm{H}), 1.5-1.2(28 \mathrm{H}), 0.88$ $(\mathrm{t}, J=6.6 \mathrm{~Hz}, 3 \mathrm{H}) .{ }^{13} \mathrm{C} \mathrm{NMR}\left(75 \mathrm{MHz}, \mathrm{CDCl}_{3}\right): \delta 72.6,65.6,55.6,34.4,31.9,29.7,29.6,29.3$, 25.7, 22.7, 14.1.

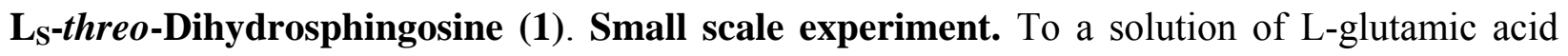
$(5.62 \mathrm{~g}, 38.2 \mathrm{mmol})$ in a hot mixture of $50 \%$ ethanol/water $(628 \mathrm{~mL}, \mathrm{v} / \mathrm{v})$, a hot solution of $11.5 \mathrm{~g}$ (38.2 mmol) rac-dihydrosphingosine (1+6) (in 95\% ethanol $(324 \mathrm{~mL}$ ) was added. The slightly turbid solution was kept at room temperature, whereupon the precipitation of crystals began after 5 minutes. The crystallization was complete in 16-20 hours. The salt (mp 165$167^{\circ} \mathrm{C}$ ) was isolated by filtration (yield, $7.5 \mathrm{~g}, 87.6 \%$ ), and was subsequently dissolved in $2 \mathrm{~N}$ sodium carbonate $(217 \mathrm{~mL})$ and extracted with chloroform $(3 \times 100 \mathrm{~mL})$. The chloroform layer was washed with a $2 \mathrm{~N}$ sodium hydroxide solution $(100 \mathrm{~mL})$, dried over anhydrous potassium carbonate, filtered and concentrated in vacuo, whereupon some $1 \mathrm{~g}(17.2 \%)$ of $(+)$ dihydrosphingosine was obtained as white crystals (mp 107-109 ${ }^{\circ} \mathrm{C}$ ). From the mother liquors, kept at $-10{ }^{\circ} \mathrm{C}$ for 20 hours, $4.5 \mathrm{~g}$ (52.6\%) Ls-threo-dihydrosphingosine-L-glutamate was isolated (white crystals; mp $146{ }^{\circ} \mathrm{C}$, dec.). This salt was converted to free base according to the procedure described above, to produce ( $2 \mathrm{~g}, 34.8 \%$ ) of (-)-dihydrosphingosine (1) (mp 107$\left.109{ }^{\circ} \mathrm{C}\right) .[\alpha]_{\mathrm{D}}{ }^{24}=-11.76(c=0.26)$. Literature: $[\alpha]_{\mathrm{D}}{ }^{27}=-11.05(c=0.29){ }^{4}$

Large scale experiment. To L-glutamic acid (48.9 g, $332 \mathrm{mmol}$ ) dissolved in 50\% ethanol $(5460 \mathrm{~mL} \mathrm{v} / \mathrm{v})$ at reflux, was added in one portion a hot solution of $100 \mathrm{~g}$ (332 mmol) racdihydrosphingosine $(\mathbf{1 + 6})\left(\mathrm{mp} 97-99^{\circ} \mathrm{C}\right)$ in $95 \%$ ethanol $(2820 \mathrm{~mL})$. The slightly turbid solution was kept at $20-25^{\circ} \mathrm{C}$, whereupon the crystallyzation began after 5 minutes. The crystallization was complete after overnight. The resulting salt was filtered off. Yield: $65.2 \mathrm{~g}(87.6 \%)$, (mp 65$67^{\circ} \mathrm{C}$ ). The mother liquors obtained after filtration were kept at $-10^{\circ} \mathrm{C}$ overnight. The resulting white crystals were filtered off $\left(\mathrm{mp} 146^{\circ} \mathrm{C}\right.$, decomposition). The mother liquors were concentrated to give a second crop of white crystals $\left(\mathrm{mp} 146^{\circ} \mathrm{C}\right)$. The salt was converted to free base according to the procedure described above and recrystallized from chloroform. (-)Dihydrosphingosine (1) $(24.2 \mathrm{~g}, 48.4 \%)$ had a melting point of $107-109{ }^{\circ} \mathrm{C}$. and $[\alpha]_{\mathrm{D}}{ }^{25}=-11.03$ $(c=0.29)$. ee: $95.3 \%$. ${ }^{1} \mathrm{H}$ NMR $\left(300 \mathrm{MHz}, \mathrm{CDCl}_{3}\right): \delta 3.73-3.52(\mathrm{~m}, 3 \mathrm{H}), 2.78-2.73(\mathrm{~m}, 1 \mathrm{H}), 2.1-$ $1.8(\mathrm{~m}, 4 \mathrm{H}), 1.54-1.20(28 \mathrm{H}), 0.88(\mathrm{t}, J=6.6 \mathrm{~Hz}, 3 \mathrm{H}) .{ }^{13} \mathrm{C} \mathrm{NMR}\left(75 \mathrm{MHz}, \mathrm{CDCl}_{3}\right): \delta 72.6,65.7$, $55.6,34.5,31.9,29.7,29.6,29.6,29.4,25.7,22.7,14.1$. 


\section{References}

1. USP Dictionary of USAN and International Drug Names, US Pharmacopeia: Rockville,:Maryland, 2000, p 636.

2. Hannun, Y. A.; Bell, R. M. Science 1989, 243, 500.

3. Schwartz, G. K.; Jiang, J.; Kelsen, D.; Albino, A. P. J. Nat. Cancer Inst. 1993, 85, 402.

4. Shibasaki, M.; Tokunaga, T.; Watanabe, S.; Suzuki, T.; Itoh, N.; Shibasaki, M. J. Org Chem. 1995, 60, 7388.

5. Shibuya, H.; Kawashima, K.; Narita, N.; Ikeda, .M.; Kitagawa, I. Chem. Pharm. Bull. 1992, 40, 1154.

6. Masui, M.; Shioiri, T. Tetrahedron Lett. 1998, 39, 5199.

7. Villard, R.; Fotiadu, F.; Buono, G. Tetrahedron: Asymmetry 1998, 9, 507.

8. Grob, C. A.; Jenny, E. F.; Utzinger, H. Helv. Chim. Acta 1951, 34, 2249.

9. Egerton, M. J.; Gregory, G. I.; Malkin, T. J. Chem. Soc. 1952, 2272.

10. Grob, C. A.; Jenny, E. F. Helv. Chim. Acta 1952, 35, 2106.

11. Sasai, H.; Suzuki, T.; Itoh, N.; Shibasaki, M. Tetrahedron Lett. 1993, 34, 851.

12. Sasai, H.; Shibasaki, M. Jp. Pat. 000090269, 1996, issued 1997.

13. Garner, O.; Park, J. M. J. Org. Chem. 1989, 54, 2361.

14. Garner, P.; Park, J. M. Org. Synth. 1991, 70, 18.

15. Rosini, G. In Comprehensive Organic Synthesis, Trost, B. M.; Fleming, I., Eds; Pergamon Press: Oxford, 1991; Vol. 2, p 321.

16. Seebach, D.; Beck, A. K.; Mukhopadhyay, T.; Thomas, E. Helv. Chim. Acta 1982, 65, 1102.

17. Beck, A. K.; Seebach, D. Chem. Ber. 1991, 124, 2897.

18. Eyer, M.; Seebach, D. J. Am. Chem. Soc. 1985, 107, 3601.

19. Atkinson, R. S. Stereoselective Synthesis, Wiley: New York 1995, pp 220-242.

20. Hino, T.; Nakakyama, K.; Taniguchi, M.; Nakagawa, M. J. Chem. Soc. Perkin Trans. I, 1986, 1687.

21. Brandli, U.; Eyer, M.; Seebach, D. . Chem. Ber. 1986, 119, 575.

22. Barrett, A. M.; Robyr, C.; Spilling, C. D. J. Org. Chem. 1989, 54, 1233.

23. Fernandez, R.; Casch, C.; Gomez-Sanchezand, A.; Vilchez, J. E. Tetrahedron Lett. 1991, 32, 3225.

24. Beck, A. K.; Seebach, D.; Colvin, E. W. Helv. Chim. Acta 1981, 64, 2264.

25. Hanessian, S.; Devasthale, P. V. Tetrahedron Lett. 1996, 37, 987.

26. Rosini, G.; Ballini, R.; Sorrenti, P. Synthesis 1983, 1014. 